LA-5782-MS

Informal Report

\title{
SNAP 19/Viking RTG \\ Solid Propellant Fire Test
}

by

E. C. Snow

UC-33

Reporting Date: October 1974 Isoued: November 1974 
In the interest of prompt distribution, this LAMS report was not edited by the Technical Information staff.

This work supported by AEC's Division of Space Nuclear Systems.

\author{
Printed in the United States of America. Available from \\ National Technical Information Service \\ U.S. Department of Commerce

$$
5285 \text { Port Royal Hoad }
$$ \\ Price: Printed Copy \$4.CJ Microfiche \$2.25
}

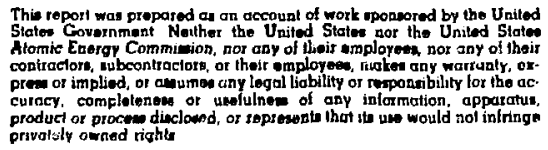




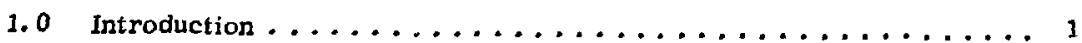

2.0 Test Description ......................... 1

2.1 Test Specimen $\ldots \ldots \ldots \ldots \ldots \ldots \ldots \ldots \ldots \ldots$

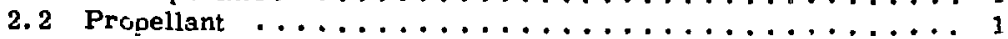

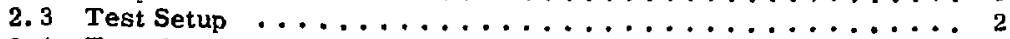

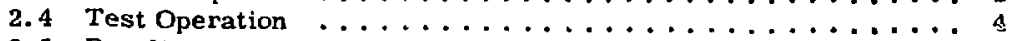

2.5 Results ...............................

3. 0 Posttest Examination. ...................... 7

3.1 Aeroshell ......................... 7

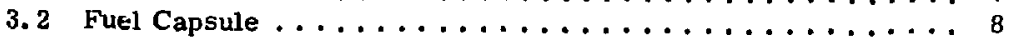

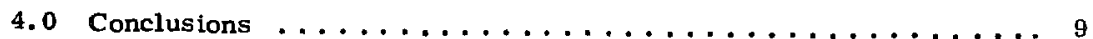

This report was prepared as an account of work
sponsored by the Unleed States Government. Ne!ther
the United States nor the United States Atomic Energy
Commission, nor any of their employees, nor any of
theis confructors, subcontractors, or their employees,
makes eny warranty, oxpress or implied, or asstimes any
legal llability or responslbility for the accuracy, com-
pleteness or usefutness of any information, opparatus,
product or process disclosed, or represents that lts use
Wousd not infringe privately owned rights.




\title{
SNAP 19/VIKING RTG SOLID PROPELLANT FIRE TEST
}

\author{
by \\ E. C. Snow
}

\begin{abstract}
On May 29, 1974, a simulant SNAP 19/Viking RTG was preheated to $121^{\circ} \mathrm{C}\left(250^{\circ} \mathrm{F}\right)$ and placed $152 \mathrm{~mm}$ from the ignited surface of a $0.5 \mathrm{~m}$ $(3 \mathrm{ft}$ ) cube of UTP-3001 solid propellant. After the $10 \mathrm{~min}$ burn, all that remained of the RTG was the heat source. However $t_{t}$ the aeroshell and fuel capsule were intact, with only some hairline cracks appearing in the outermost part of the clad on the ends of the fuel capsule.
\end{abstract}

\subsection{INTRODUCTION}

In the process of gathering information to be used in the safety analysis for the Viking program, many safety tests have been conducted. One such test is the solid propellant fire test reported here. The objective of this test was to subject a SNAP 19/Viking RTG to a solid propellant fire environment in order to evaluate the response of the Viking RTG to such an environment and, in particular, to determine the fuel containment ability of the heat source fuel capsule.

\subsection{TEST DESCRIPTION $2,1 \quad$ Test Specimen}

The test specimen was a test bed generator as defined by Teledyne ESD drawing NSK 1262. This contained a complete assembly of insulation, thermoelectrics, etc. The fuel capsule of Pioneer length contained PMC simulant disks, as in Teledyne ESD drawing 45'A6020020. The simulant was a $\mathrm{ThO}_{2}$-Mo cermet. The generator housing was from a defueled Pioneer RTG and differed from the actual Viking flight design in that the fins were
$93 \mathrm{~mm}$ shorter than those on the Viking RTG. Also, the vent tubes are not in the Viking flight generators. Neither of these deviations should influence the fuel containment response of the system. The two vent tubes, shown on one end of the RTG in Fig. 2.1, were cut off flush to the housing before the test, so that the RTG could be placed in the fire with that end down.

\section{$\underline{2} 2 \quad$ Propellant}

The solid propellart used was UTP 3001 which is used in the solid boosters of the Titan IIIC vehicle on which the Viking spacecraft will be launched. UTP 3001 contains powdered aluminum and ammonium perchlorate dispersed in a rubber binder. Several other additives are present in small percentages. The propellant block was inhibited so as to burn only on one face to give the maximum burning time. The $0.9 \mathrm{~m}$ ( $3 \mathrm{ft})$ dimension corresponds to the web thickness of the Titan IIIC booster motors. The rationale is that a piece of an actual motor could not burn any longer than the time necessary to burn through a full web thickness. The steel plate was added to test for possible 

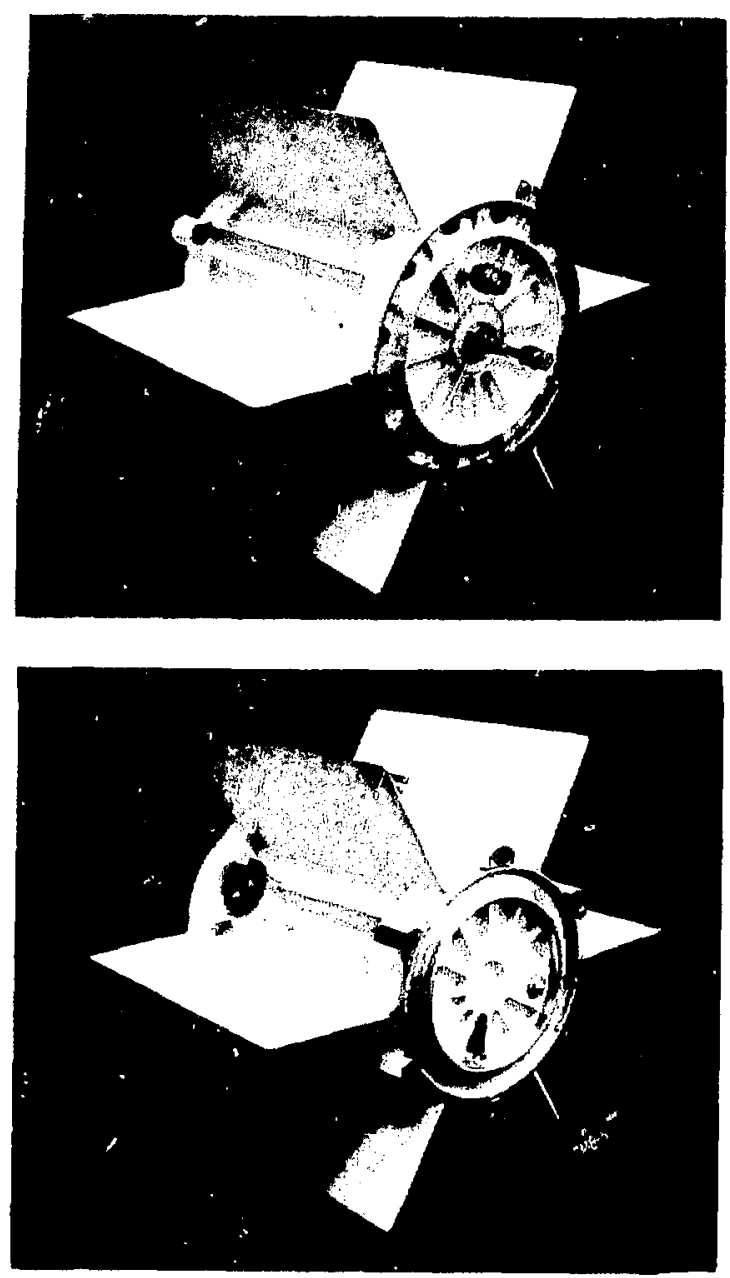

Fig. 2. 1 Two views of the Viking test RTG S/N-37, asi received at $L A S L$ for fire test. (The scale shown is $152.4 \mathrm{~mm}$ long.)

effects caused by the presence of steel in the fire as th: actual booster motor las a steel casing and it is thought by some that a rocket abort or destruct could not produce a large piece of solid propellant without having steel casing attached.

\section{$\underline{2.3} \quad$ Test Setup}

The test was conducted at one of the burn pads in the S-Site area at LASL. The pad, surrounded by a fence about $15 \mathrm{~m}$ ( $50 \mathrm{ft}$ ) a way, consisted of lightly packed sand and was a square approximately $15 \mathrm{~m}(50 \mathrm{ft})$ on a side. The $0.9 \mathrm{~m}$ (3 ft) cube of solid propellant (UTP 3001), with all but one surface inhibited, was placed near the center of the pad with the uninhibited surface in a vertical position. The block of propellant was oriented such that the uninhibited surface faced west, because the predorninant winds in this area are from the southeast and it was hoped that these winds would aid in carrying the hot gases and smoke away from the cameras and the control bunker.

The test specimen was placed on the sand pad with fin tips approximately $152 \mathrm{~mm}$ (6 in.) from the uninhibited surface of the propellant, as shown in Fig. 2.2. Also shown in this figure is the $9.5 \mathrm{~mm}$ (3/8 in.) thick steel plate placed on top of the propellant to simuls:a a piece of the solid rocket motor casing. The lead wires for the thermocouple placed on the housing of the RTG can also be seen. Not shown in this figure is the small trench, at the base of the uninhibited surface of the propellant, that was filled with smokeless powder to insure complete and uniform ignition of the propellant face. The smokeless powder was ignited with squibs operated from the control bunker.

The test plan required preheating the test specimen to a fin root temperature of $121^{\circ} \mathrm{C}$ $\left(250^{\circ} \mathrm{F}\right)$ prior to the burn. To accomplish this preheat, an oven was used that was several kilometers away from the burn pad. An insulated container was used to transport the heated RTG from the oven to the pad. This insulated container and RTG with a thermocouple attached to the fin root can be seen in the preheat oven in Fig. 2. 3.

To photograph the fire, two cameras were set up to take color motion pictures. One camera was situated due south of the propellant approximately $45 \mathrm{~m}$ away and was set for over-all coverage of the burn. The other camera was closer, approximately $30 \mathrm{~m}$, elevated about $3 \mathrm{~m}$ above the ground, and focused on the burning surface of the propellant from the southwest. Both cameras were preset to run from a few seconds before ignition until the burn was complete, approximately 10 min later. 


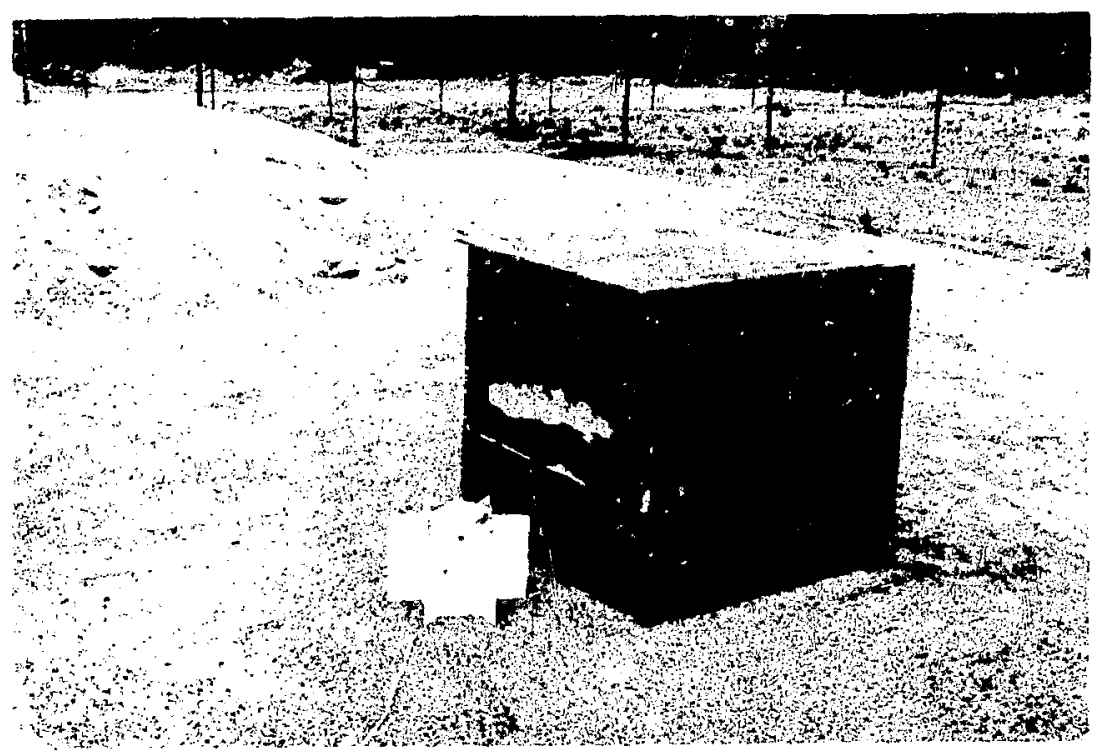

Fig. 2.2 Viking test RTG in place in front of the uninhibited face of the cube of solid propellant, with the $9.5 \mathrm{~mm}(3 / 8 \mathrm{in}$.) thick steel plate on top of the propellant.

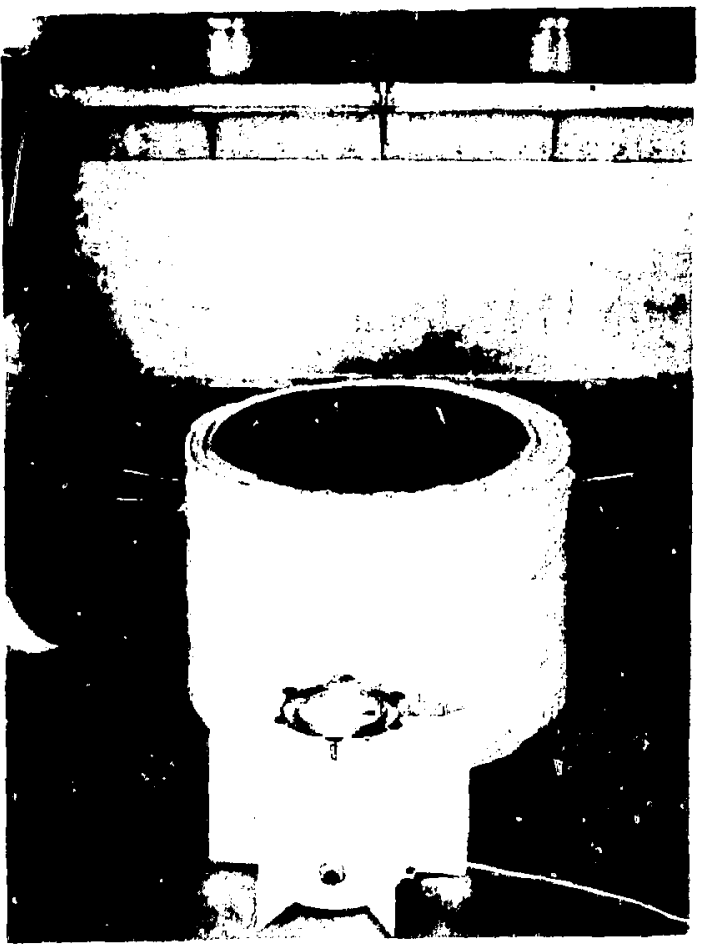

Fig. 2.3 Viking test RTG and insulated transport ccntainer in preheat oven.
To record temperatures near the burning surface of the propellant, an array of thermocouples was set up as shown in Fig. 2.4. The two thermocouples placed closest to the burning surface of the propellant were of the tungsten-

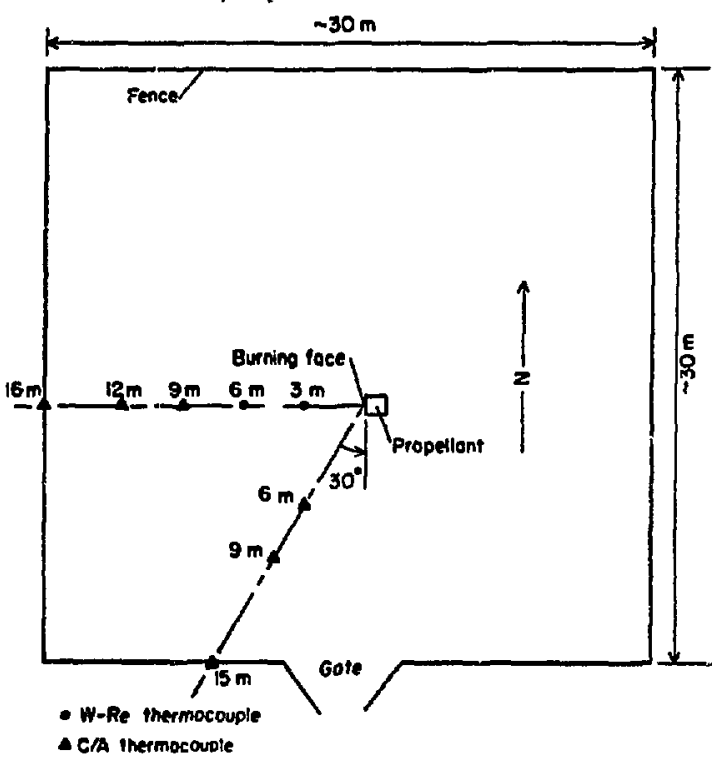

Fig. 2.4 Map of burn pad area, showing location of propellant and thermocouple array. 
rhenium type and those farther away were of the Chromel-Alumel thermocouple type. A ChromelAlumel thermocouple was also attached to one of the fins of the RTG housing to monitor the housing temperature continuously throughout the preheat and the first part of the burn.

\subsection{Test Operation}

On May 28, 1974, approximately $17 \mathrm{~h}$ before the test, the Viking RTG was placed in its insulated transport container in the oven and the oven set for approximately $205^{\circ} \mathrm{C}\left(400^{\circ} \mathrm{F}\right)$. The test specimen was then allowed to soak in the oven at that temperature until 10:00 A. M. on May 29, 1974. At that time it was removed from the oven, still in its insulated container, and transported directly to the burn pad.

Or: the morring of May 29, the weather was mostly cleal, the air temperature was approximately $18^{\circ} \mathrm{C}\left(64^{\circ} \mathrm{F}\right)$, and the wind was mainly from the north at approximately $20 \mathrm{~km} / \mathrm{h}$ (11 mph). During the test, the winds varied in speed and shifted between west and east, through north, but never exceeded $20 \mathrm{~km} / \mathrm{h}$. The barometric pressure remained at $1.03 \times 10^{5} \mathrm{~Pa}(30.4 \mathrm{in}$. of $\mathrm{Hg})$ throughout the test.

With the cube of solid propellant in place on the pad and the steel plate on top of the propellant, the smokeless powder and igniter squibs were placed in the trench at the base of the uninhibited surface. The preheated Viking test RTG was removed from its insulated transport container and placed next to the uninhibited surface of the propellant. The igniter squibs were quickly attached to the trigger control mechanism and all personnel removed to the control bunker.

Approximately $20 \mathrm{sec}$ before ignition, the recorders for the array of thermocouples were turned on and checked for proper ambient air readings. About $10 \mathrm{sec}$ later, the cameras were switched on. The squibs were fired at 10:10 A. M. , with the ignition of the propellant surface occurring a second or two later. The entire face of the propellant was burning within $1 \mathrm{sec}$ of squib ignition as determined from the films. The propellant burned for approximately 10 min before it was exhausted. Ten minutes after coinpletion of the burn, the area just outside the burn pad was monitored for radioactive contaminatioll, and none was found. The remains of the RTG were observed from outside the fence at that time, but no personnel were allowed to go inside until the area had a sufficient time to cool down.

At approximately 2:00 P. M. , personnel were allowed inside the fenced area for still photographs, radioactive contamination survej, and clean up. The remains of the RTG and the sand on the pad in the immediate vicinity of the burn were photographed and removed for posttest: examinations.

2. 5 Results

The thermocouple on the fin root of the RTG indicated that the housing temperature was about $115^{\circ} \mathrm{C}\left(240^{\circ} \mathrm{F}\right)$ at the time of ignition. Within seconds after ignition, this thermocouple went off scale $\left(\mathrm{T}>1200^{\circ} \mathrm{C}\right)$.

Of the thermocouples in the array to measure the temperature near the burning surface of the propellart, only the Chromel-Alumel type gave useful readings. These temperatures are plotited as a function of time in Figs. 2.5 and 2.6, It can be seen that the maximum temperature recorded was about $550^{\circ} \mathrm{C}\left(1022^{\circ} \mathrm{F}\right)$ on the thermocouple $6 \mathrm{~m}$ from the burning surface and on a line forming an angle of $30^{\circ}$ with the surface (see Fig. 2.4). The tungsten-rhenium thermocouple $6 \mathrm{~mm}$ directly in front of the propellant gave a single reading of $670^{\circ} \mathrm{C}\left(1238^{\circ} \mathrm{F}\right)$ before it failed. However, there is no way of knowing whether this was near the maximum temperature or not.

In viewing the motion pictures of the burn from the nearest camera, it was noted that shortly after ignition of the propellant, just before the RTG was obscured by the flame and smoke, the outer fins of the RTG housing were burning, with 


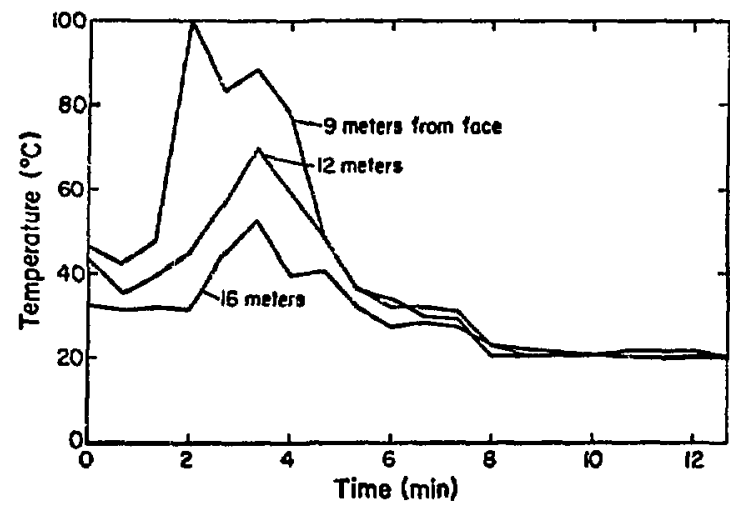

Fig. 2.5 Temperatures as a function of time recorded by the Chromel-Alumel thermocouples on the centerline perpendicular to the burning surface of the propellant.

the flames propagating along the edge of the fins.

The propellant burned for approximately $10 \mathrm{~min}$, sending a large column of thick white smoke into the air. The intensity of the flames and the size of the column of smoke can be seen in Figs. 2.7 and 2.8. These photographs were taken from a point $1.8 \mathrm{~km}$ ( 1 mile) away from the burn pad. Measurements of Fig. 2.7 gave a smoke

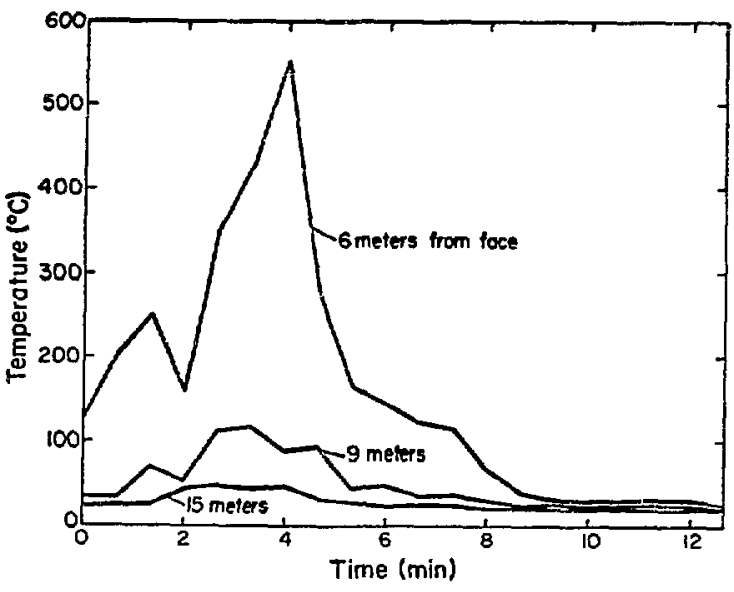

$F^{i g . ~ 2.6 ~ T e m p e r a t u r e s ~ a s ~ a ~ f u n c t i o n ~ o f ~ t i m e ~ r e-~}$ corded by the Chromel-Alumel thermocouples on a line $30^{\circ}$ to the burning surface of the propellant.

column height of more than $100 \mathrm{~m}$.

When the propellant was exhausted, all

th. remained of the RTG was the heat source, with the fuel capsule intact inside the intact graphite aeroshell. The aeroshell can be seen in the left center of Fig. 2.9 and the center of Fig. 2.10.

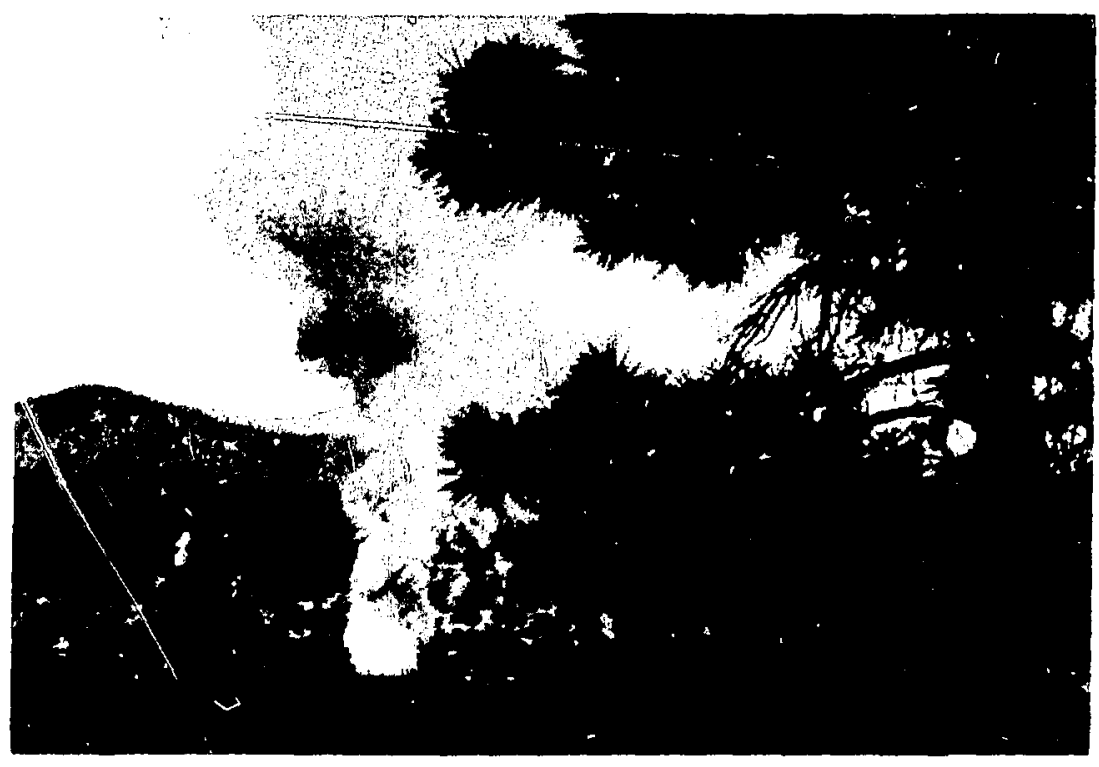

Fig. 2, 7 Long-range photograph of Viking fire test. 


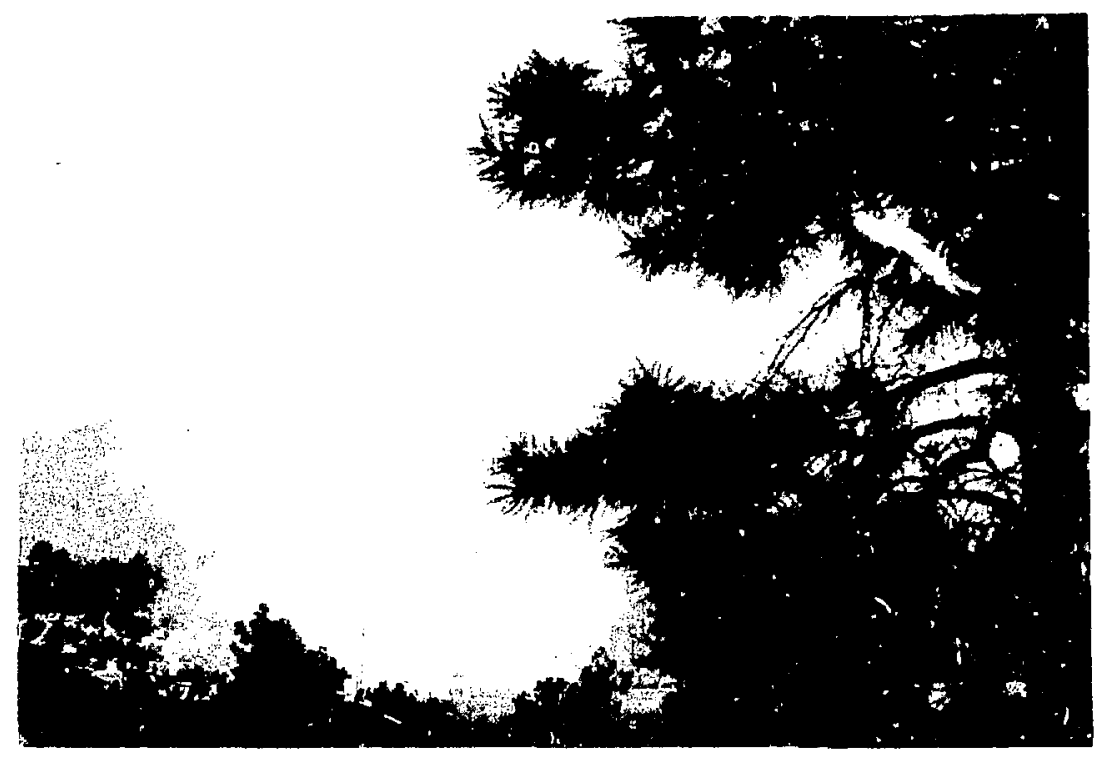

Fig. 2. 8 Long-range photograph of Viking fire test.

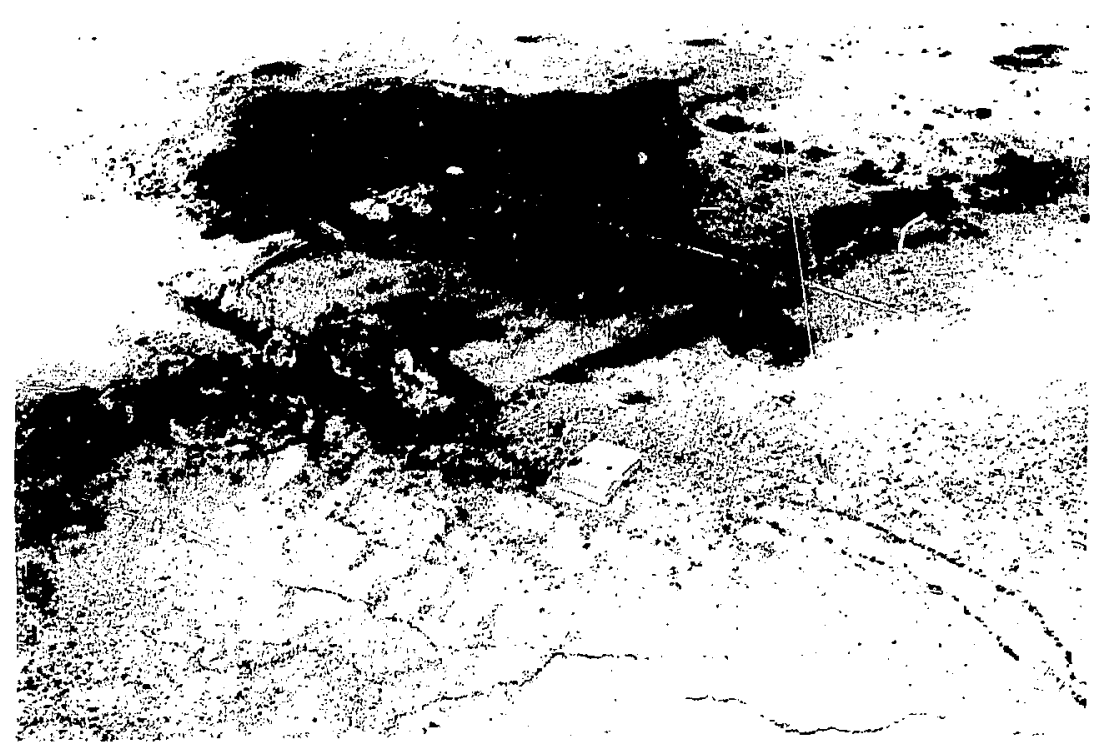

Fig. 2.9 Burn pad area after Viking fire test. 


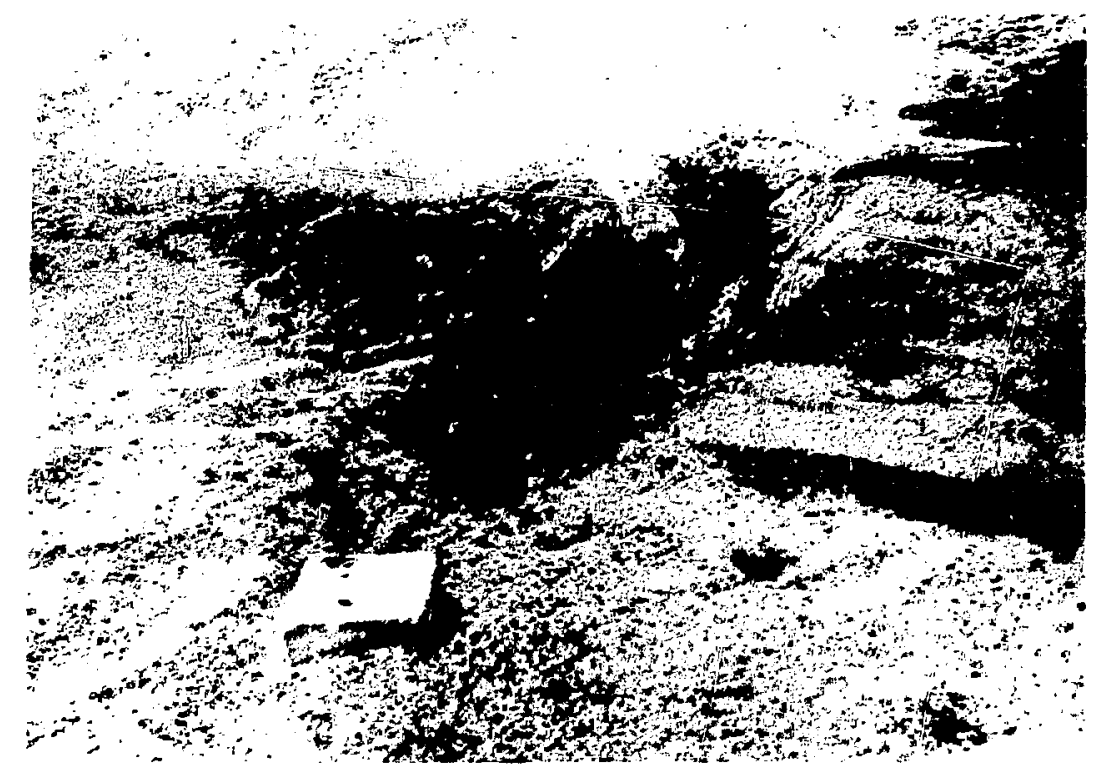

Fig. 2.10 Remains of Viking lest RTG on burn pad after lire test.

In both photographs the trench originally located just in front of the uninhibited propellant surface is evident, and the initial RTG Incation can also be seen. The outline of the fins of the RTG housing that were away from the propellant are also apparent in these two photographs.

\subsection{POSTTEST EXAMINATION \\ 3.1. Aeroshell}

The only thing left of the Viking RTG housing and thermoelectrics was a small piece of a spring. The aeroshell, on the other hand, was completely intact, as can be seen in Figs. $3,1,3.2$, and 3.3 . The bulk of the material adhering to the graphite of the aeroshell is fused silicate slag from the sand of the burn pad. The white slag, seen mostly on the top and sides of the aercshell in these photographs, is primarily alumira (propellant combustion product). It is of interest to note that not only was the aeroshell intact, but the edges were still sharp and distinct. This indicates that very little of the graphite of the aeroshell burned away in the fire environment.
When the aeroshell was disassemiled, as shown in Figs. 3.4 and 3.5, the zirconia retaining cups at either end of the fuel capsule were found to be cracked and came out in pieces as the fuel

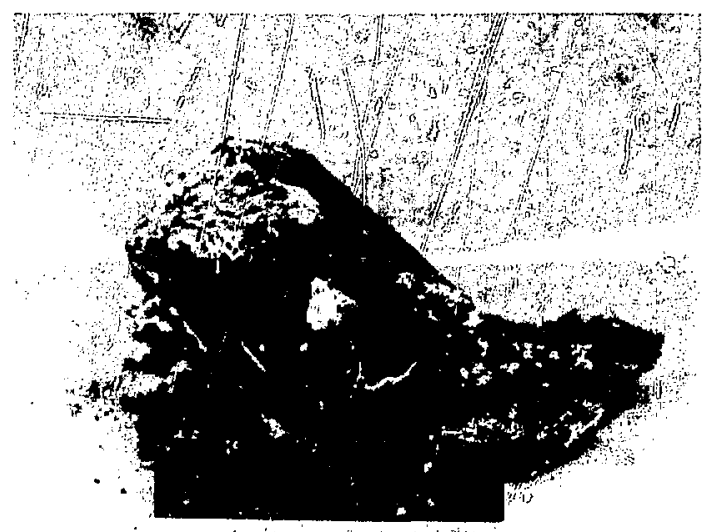

Fig. 3.1 Graphite aeroshell of Viking test RTG imbedded in slag from the and of the burn pad. (The scale shown is $152.4 \mathrm{~mm}$ Iong. ) 


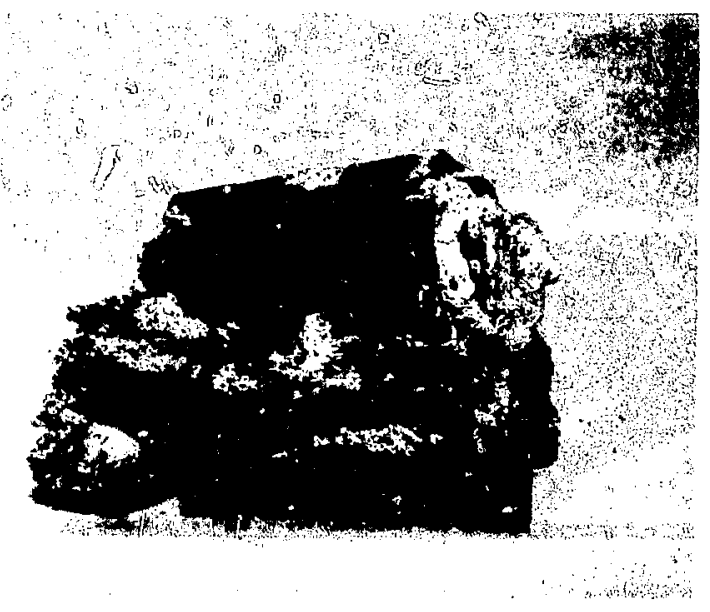

Fig. 3,2 Side view of aeroshell of Viking test RTG heat source. (Scale shown is 152. $4 \mathrm{~mm}$ long.)

capsule was removed.

\section{$3.2 \quad$ Fuel Capsule}

The fuel capsule was completely intact and undamaged except for cracks in the clad seen in Figs. 3.6 and 3.7. There is some question as to whether these cracks were caused by the thernal stresses experienced by the capsule during the

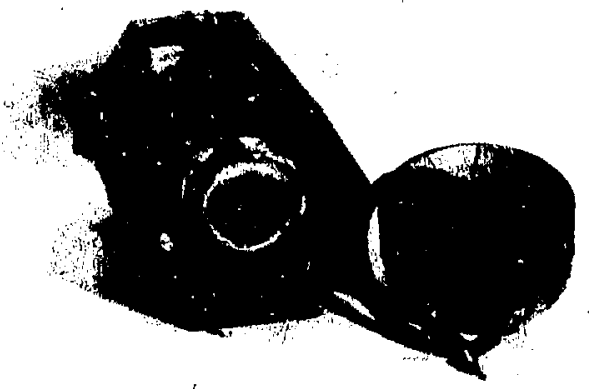

Fig. 3.4 Graphite aeroshell of Viking test RTG heat source with end cap removed.

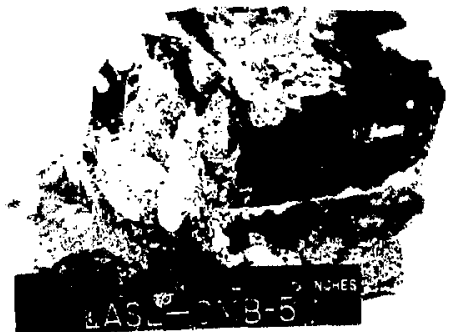

Fig. 3.3 End view of aeroshell of Viking test RTG heat source showing alumina adhered to cap. (Scale shown is $152.4 \mathrm{~mm}$ long.)

fire or were a result of the vibration tests performed on the RTG prior to the fire test. Radiographs of the capsule indicated that these cracks were only in the Pt-Rliclad and did not penetrate the strength member. Though these crack:s rlid not affect the short time containment ability of the capsule, they would reduce the time required for

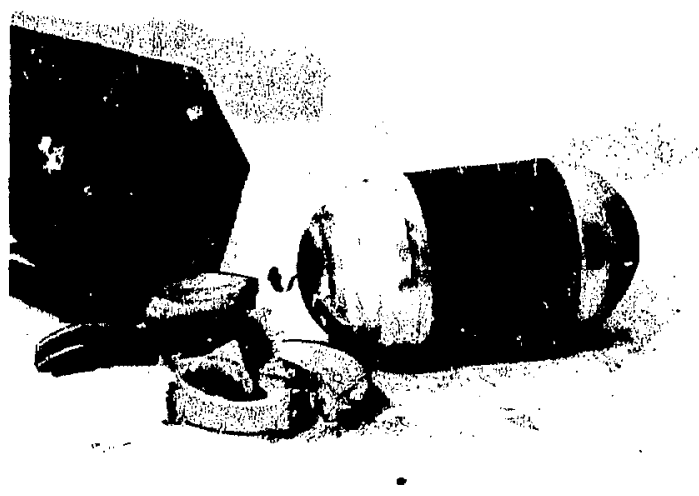

Fig. 3.5 Fuel capsule of Viking test RTG heat source removed from aeroshell. 


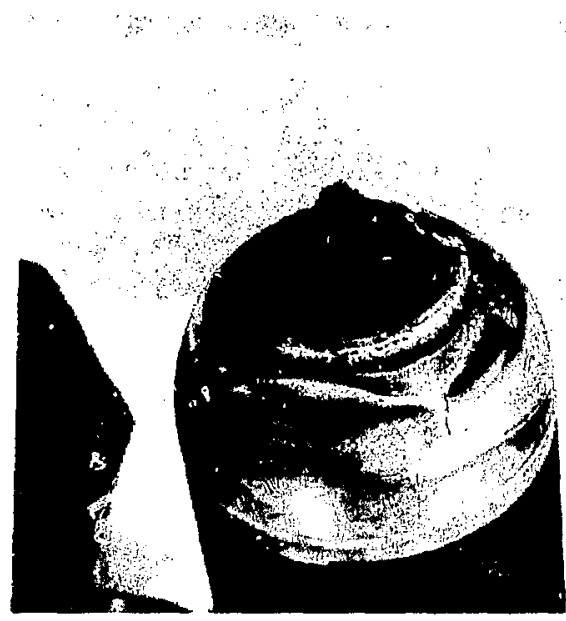

Fig. 3.6 Vented end of fuel capsule from Viking test RTG.

$\mathrm{T}-111$ oxidation during the postfire exposure of a hot, live-fuel capsule. No evidence of thoria could be detected in the area of the cracks or elsewhere on the fuel capsule. As the capsule was to be used for an impact test, no destructive postmortem was done.

\section{0 CONCLUSIONS}

Based on the results of this test and the posttest analysis, the following conclusions can be reached.

1. The converter of the Viking RTG will probably be completely burned away in a solid propellant fire environment, even if the block of propellant were smaller and the burn time shorter.

2. If the aeroshell is intaci, when introduced to the solid propellant fire environment, it should remain intact through wny fire of up to $10 \mathrm{~min}-$

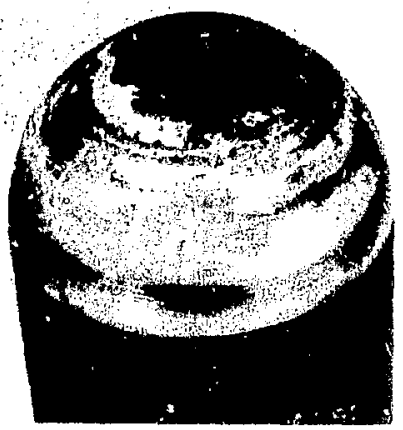

Fig. 3.7 Unvented end of fuel capsule from Viking test RTG.

duration.

3. The fuel capsule contained in an intact aeroshell should not be breached in a solid propellant fire environment and should, therefore, not result in the immediate release of radioactive contamination. However, cracking of the outer clad would probably result in an increase in the $T-111$ oxidation rate and subsequent failure.

\section{ACKNOWLEDGMENTS}

The author wishes to thank N. K, Kernodle and the personnel at the LASL S-Site burn pad for their continuing cooperation throughout the operation of this test. A special thanks also goes to E. M. Cramer for the posttest examinations and photography. The helpful comments and suggestions offered by R. N. R. Mulford and S, E. Bronisz were also appreciated. 